\title{
Predictive accuracy of backpropagation neural network methodology in evapotranspiration forecasting in Dédougou region, western Burkina Faso
}

\author{
S Traore ${ }^{1,2}$, Y M WANG ${ }^{3, *}$ and W G $\mathrm{ChUNG}^{3}$ \\ ${ }^{1}$ Ministry of Research and Scientific Innovation, INERA-Farako-ba, BoboDioulasso, Burkina Faso, Africa. \\ ${ }^{2}$ African Policy Center, United Nations Economic Commission for Africa (UNECA), Addis-Ababa, Ethiopia. \\ ${ }^{3}$ Department of Civil Engineering, National Pingtung University of Science and Technology, Pingtung, Taiwan, \\ 91201, R.O.C. \\ ${ }^{*}$ Corresponding author.e-mail: wangym@mail.npust.edu.tw
}

The present study evaluates the predictive accuracy of the feed forward backpropagation artificial neural network (BP) in evapotranspiration forecasting from temperature data basis in Dédougou region located in western Burkina Faso, sub-Saharan Africa. BP accuracy is compared to the conventional Blaney-Criddle (BCR) and Reference Model developed for Burkina Faso (RMBF) by referring to the FAO56 Penman-Monteith (PM) as the standard method. Statistically, the models' accuracies were evaluated with the goodness-of-fit measures of root mean square error, mean absolute error and coefficient of determination between their estimated and PM observed values. From the statistical results, BP shows similar contour trends to PM, and performs better than the conventional methods in reference evapotranspiration (ET_ref) forecasting in the region. In poor data situation, BP based only on temperature data is much more preferred than the other alternative methods for ET_ref forecasting. Furthermore, it is noted that the BP network computing technique accuracy improves significantly with the addition of wind velocity into the network input set. Therefore, in the region, wind velocity is recommended to be incorporated into the BP model for high accuracy management purpose of irrigation water, which relies on accurate values of ET_ref.

\section{Introduction}

A water balance computer simulation model application for irrigation planning in Burkina Faso required a reliable estimation of evapotranspiration to improve the water use efficiency. Since 2001, Burkina Faso is promoting the irrigation development through the small scale irrigation project. Nowadays, the small scale irrigation project in the country has pushed effective irrigation planning and management techniques to the forefront of its forthcoming objectives. For reaching this goal, the project has shown a real interest for the application of water balance computer-based simulation techniques for irrigation water management. Evapotranspiration is a principal component of ground and surface water budgets and to properly quantify crop water needs. According to Kant and Badarinath (1998), evapotranspiration is a key element in the water balance studies and crop yield modelling. However, direct estimation of evapotranspiration for the calculation of crop water requirements is difficult. Instead, reference evapotranspiration is used for the

Keywords. Temperature basis models; intelligent computing; irrigation management; sub-Saharan Africa. 
estimation of evapotranspiration. Therefore, reference evapotranspiration (ET_ref) is highly required for agricultural water management due to persistence of water resources rarity and growing of the world population. In the developing world, particularly in African arid and semiarid regions, shortage of water has caused food shortages and constrained economic growth. Food shortage is a source of political instability for the entire region as seen from the recent food crisis demonstration in most Africans countries. Therefore, water resources management is a key issue for enhancing agricultural productivity and hence attain food security.

In Burkina Faso, efficient water management is central for agricultural production because the crops are constantly under the influence of low rainfall and high temperature. Efficient water management requires an accurate ET_ref value, which can be derived from the meteorological variables. Fisher et al. (2005) indicated that ET_ref is a major component in terrestrial water balance and net primary productivity models, but it is difficult to measure and predict. The most common Penman-Monteith (PM) equation has been recommended by the Food and Agriculture Organization of the United Nations as the sole universally accurate method for estimating ET_ref. According to Alexandris et al. (2006), PM is now widely used by agronomists, irrigation engineers and other scientists in field-practice and research. However, the large number of weather input data required by the PM equation is often difficult and expensive to obtain for practical applications in many countries of the world.

Penman-Monteith equation computes ET_ref using the minimum and maximum air temperatures, relative humidity, wind velocity and sunshine hour data. As a result, reliable ET_ref estimation from limited data is extremely needed for agricultural water efficient management in Burkina Faso. Marti et al. (2010) reported that there are only a limited number of stations where sufficient reliable climatic data are available for the application of FAO-56 PM. Thus, the development of more efficient ETo predicting tools is now of great importance, especially when only scant climatic data are available. Traore et al. (2007) and Wang et al. (2008) have indicated a constraint to computerize the irrigation information in Burkina Faso due to the enormous data required by the PM equation. Irrigation data required is lacking in most of the production sites in the country (Wang et al. 2009a, b). Hence, the conventional approaches of Blaney-Criddle (BCR) and Reference Model for Burkina Faso (RMBF) previously developed are still used for ET_ref estimation because of the advantage of their simplicity requiring only air temperature data. According to Smith et al. (1996) and Wang et al. (2009c), although the conventional methods use few weather data, they do not have a universal suitability. Alexandris et al. (2006) reported that they are often unable to capture the effect of some important climatic parameters, which may affect ET_ref. According to Meza (2005), these methods miss the opportunity to incorporate some weather information. The performance quality of empirical equations and their local calibrations is to be questioned in a large variety of climatic contexts (Marti and Gasque 2010).

In past decades, scientists paid considerable attention to another approach which is the artificial neural network (ANN) applied in diverse fields of hydrology engineering forecasting and modelling. ANN is capable of modelling any arbitrarily complex nonlinear process by drawing the estimate function directly from the training data (Kerh et al. 2009; Wang and Traore 2009). ANN application in hydrology due to its high nonlinear functional characteristic has provided many advantages rapidly in hydrology including rainfall-runoff modelling (Firat 2008); suspended sediment forecasting (Wang et al. 2009d), crop consumptive water requirements (Traore et al. 2010b) and evapotranspiration estimation (Kiz̧i 2006). ANN was potentially used to model ET_ref as a function of climatic variables. In the past, Sudheer et al. (2003) and Zanetti et al. (2007) in their ET_ref estimation simplified the neural network inputs data to air temperature, extraterrestrial solar radiation, and daily light hour. From the study done by Khoob (2008a), the daily light has not been considered in the estimation of ET_ref in Iran semiarid zone. Landeras et al. (2008) have used similar dataset without the daily light to estimate successfully the ET_ref. The above reported studies show that the application of ANN to forecast ET_ref in semiarid climatic zone of Africa is poorly referenced in literature. However, reliable ET_ref estimation from limited climatic data is highly desired in Africa, since it is very costly to dispose a complete set of meteorological equipment.

Therefore, the performance of the feed forward backpropagation neural network (BP) algorithm ANN type is investigated in the present study for ET_ref forecasting based on temperature data. In the study, the minimum and maximum air temperatures $\left({ }^{\circ} \mathrm{C}\right)$, and extraterrestrial solar radiation $\left(\mathrm{mm} \mathrm{day}^{-1}\right)$ were adopted as the input variables of the neural network and ET_ref as the output variable. In fact, three methods were employed including the $\mathrm{BP}, \mathrm{BCR}$, and $\mathrm{RMBF}$ for forecasting the ET_ref in comparison with the true PM values. For this study, data have been collected from Dédougou meteorological station located in western Burkina Faso, sub-Saharan Africa. 


\section{Material and methods}

\subsection{Location and meteorological information characterization}

The area investigated is in a semiarid region with low rainfall and high temperatures and is situated in the western region of the Burkina Faso. The country has three large climatic zones, which are the Sudanian, Sudano-Sahelian and Sahelian zones. Figure 1 represents the annual average of precipitation for 12 years collected in this study. In figure 1, the precipitation is classified into three layers by using Geographical Information System (GIS) interface. The data show that Dédougou is mainly located in the Sudano-Sahelian zone at $300 \mathrm{~m}$ altitude, $12^{\circ} 47 \mathrm{~N}$ latitude and $3^{\circ} 48 \mathrm{~W}$ longitude. The decadal climatic data used for this study were recorded at the meteorological station of Dédougou from 1996 to 2007. The data for this study were comprised of maximum and minimum air temperatures $\left({ }^{\circ} \mathrm{C}\right)$, precipitation $(\mathrm{mm})$, relative humidity (\%), wind speed $\left(\mathrm{km} \mathrm{day}^{-1}\right)$ and sunshine duration (hours). The region has two seasons; a rainy season (short) from May to September and a dry season (long) from October to April. The region has an annual average rainfall of $809 \mathrm{~mm}$. In the region, $80.5 \%$ of rainfall occurs between June and September with a peak in August $(227 \mathrm{~mm}$ ). The annual average air temperature ranges from $22.2^{\circ}$ to $38.8^{\circ} \mathrm{C}$ and $18.3^{\circ}$ to $40.3^{\circ} \mathrm{C}$ in rainy and dry season, respectively. The sunshine average is about $8.6 \mathrm{~h}$. The mean of relative humidity are
$33 \%$ in dry season and $69 \%$ in rainy season with an annual average of $48 \%$. Wind velocity recorded at $2 \mathrm{~m}$ above the ground has an annual average of $147 \mathrm{~km} \mathrm{day}^{-1}$. The wind speed annual averages in rainy and dry season are 141 to $150 \mathrm{~km} \mathrm{day}^{-1}$, respectively. The entire country suffers from the dry east wind called Harmattan, blowing the heat from March to May.

\subsection{Applied evapotranspiration models}

The models applied to estimate the reference evapotranspiration are the FAO56 Penman-Monteith (PM), Blaney-Criddle (BCR) and Reference Model for Burkina Faso (RMBF) given as the following:

- Penman-Monteith (PM) equation used in this study is represented as (Allen et al. 1998):

$$
\text { ET_ref }=\frac{0.408 \Delta\left(R_{n}-G\right)+\gamma \frac{900}{T+273} u_{2}\left(e_{s}-e_{a}\right)}{\Delta+\gamma\left(1+0.34 u_{2}\right)},
$$

where ET_ref is the reference evapotranspiration $\left(\mathrm{mm} \mathrm{day}^{-1}\right) ; R_{n}$ the net radiation at the crop surface $\left(\mathrm{MJ} \mathrm{m}^{-2}\right.$ day $\left.^{-1}\right) ; G$ the soil heat flux density $\left(\mathrm{MJ} \mathrm{m} \mathrm{m}^{-2}\right.$ day $\left.^{-1}\right) ; T$ the mean daily air temperature at $2 \mathrm{~m}$ height $\left({ }^{\circ} \mathrm{C}\right) ; u_{2}$ the wind speed at $2 \mathrm{~m}$ height $\left(\mathrm{ms}^{-1}\right) ; e_{s}$ the saturation vapour pressure $(\mathrm{kPa}) ; e_{a}$ the actual vapour pressure $(\mathrm{kPa})$; $e_{s}-e_{a}$ the saturation vapour pressure deficit $(\mathrm{kPa})$;

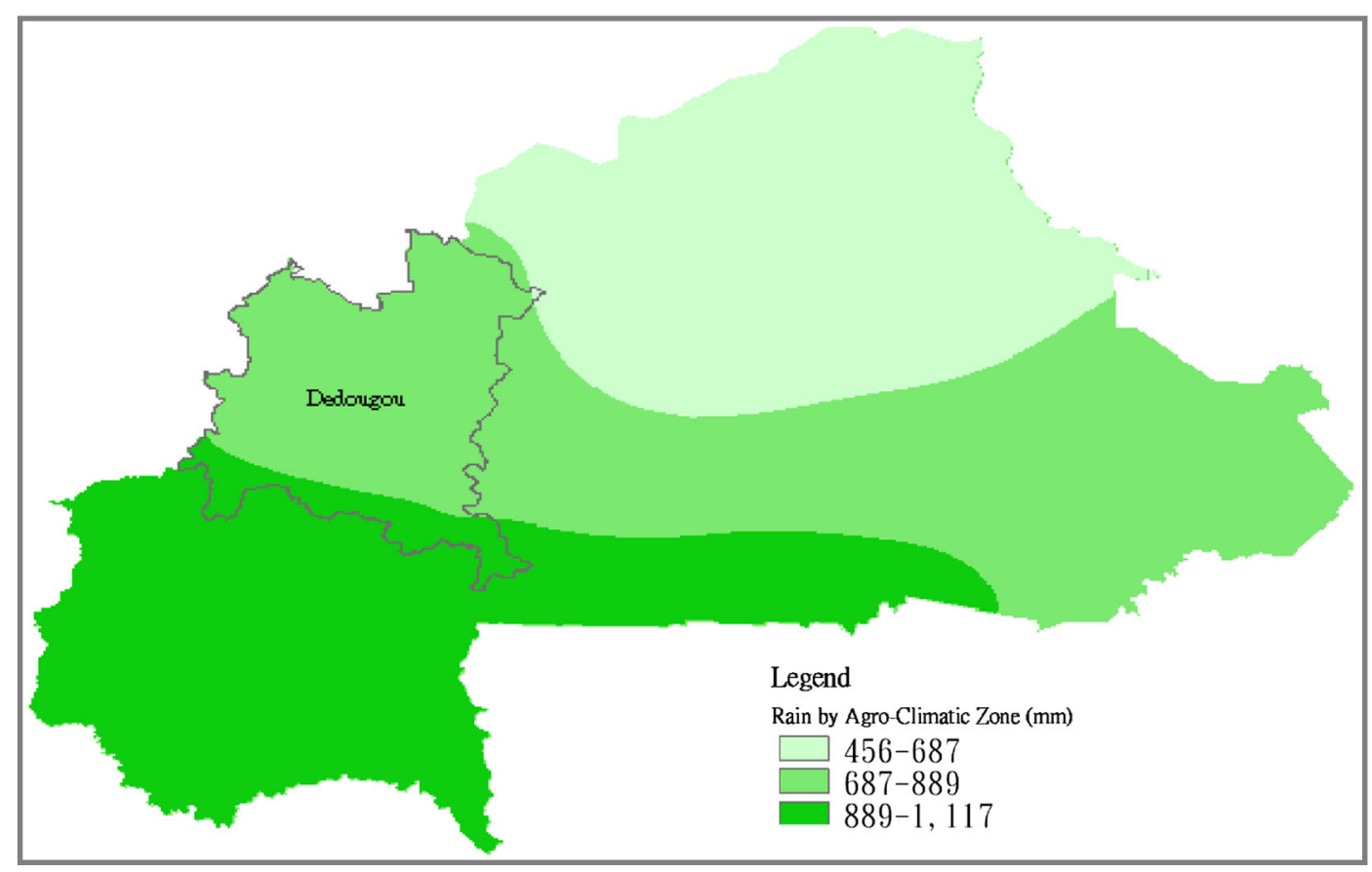

Figure 1. Agro-climatic zone based on the annual average of 12-year rainfall data between 1996 and 2007. 
$\Delta$ the slope vapour pressure curve $\left(\mathrm{kPa}^{\circ} \mathrm{C}^{-1}\right)$; and $\gamma$ the psychrometric constant $\left(\mathrm{kPa}^{\circ} \mathrm{C}^{-1}\right)$.

- Blaney-Criddle (BCR) equation used is expressed as the following (Doorenbos and Pruitt 1977):

$$
\text { ET_ref }=p\left(0.46 T_{\text {mean }}+8.13\right)
$$

Reference Model for Burkina Faso (RMBF) was previously proposed by Wang et al. (2007) for ET_ref estimation in Burkina Faso. RMBF was introduced to estimate ET_ref for agricultural water management purpose in order to solve the difficulty of climatic data unavailability in Burkina Faso. The equation is expressed as the following:

$$
\begin{aligned}
\text { ET_ref }= & p\left(0.23 T_{\text {mean }}+4.065\right) \\
& +0.0023\left(T_{\max }-T_{\min }\right)^{0.5} \\
& \times\left(0.5 T_{\text {mean }}+8.9\right) R_{a},
\end{aligned}
$$

where in equation (2) $T_{\text {mean }}$ stands for the mean temperature $\left({ }^{\circ} \mathrm{C}\right)$ and $p$ stands for the mean daily percentage of annual daytime hours according to the latitude; in equation (3) $T_{\max }$ and $T_{\min }$ stand for the maximum and minimum temperatures $\left({ }^{\circ} \mathrm{C}\right) ; R_{a}$ is the extraterrestrial radiation $\left(\mathrm{mm} \mathrm{day}^{-1}\right)$.

\subsection{Applied neural network algorithm}

This study used the latest version of the Neuro Solution 5.0 software presented by the Neuro Dimension, Inc. Intelligence software solution. The artificial neural network (ANN) algorithm selected for this study was the feed forward backpropagation neural network (BP). The BP is a supervised learning technique used for training the neural networks. It is a gradient descent technique to minimize the error criteria. The BP has been widely used in approximating complicated nonlinear functions. The neural network structure in this study possessed a three-layer learning network consisting of an input layer, a hidden layer and an output layer (figure 2). The decadal data collected in Dédougou has 432 patterns (from January 1996 to December 2004), and it was divided in three parts for the purpose of training (70\%), crossvalidation $(20 \%)$ and testing $(10 \%)$. The training data are used to train the network by minimizing the error data. The cross-validation data are used to find the network performance by monitoring the training and guarding against overtraining. Then, the testing data are used for checking the overall performance of trained and validated network. The idea of cross validation is to split the training set into two that include train set and validation set. The early stopping procedure was used as the criterion to finalize the training, and running times and numbers were increased to have average weight change of initial random. So, the cross validation is to choose in supervising the representation in which the error of the validation set is minimum, as learning can continue until the error of the validation set starts to increase, then the network will stop. Since the objective was to forecast ET_ref from climatic variables, this study has considered the variables, minimum $\left(T_{\min }\right)$ and maximum $\left(T_{\max }\right)$ air temperatures, and extraterrestrial radiation $\left(R_{a}\right)$ as inputs; and then ET_ref values as the output variables of the neural network (figure 2).

The BP neural network algorithm during the training process has two passes of propagation (forward/backpropagation) for calculating all the gradients. For the forward pass, the activation pattern of an input vector is propagated through the network to produce an output. Each input $x_{i}$ is multiplied by an adjustable constant $w_{i j}$ (weight) before being fed to the $i$ th processing element (PE) in the output layer, yielded by the equation (4). In this study, the network activation function was the tan-sigmoid function bounded between $[-1 ; 1]$, and defined as $\left[f=\left(e^{x}-e^{-x}\right) /\left(e^{x}+e^{-x}\right)\right]$. In the forward propagation, the computation of the output is carried out layer by layer, i.e., from the input to the output in the forward direction, and the error between desired outputs and actual outputs is computed.

In the backpropagation pass, the adjustment of the interconnecting weights during the training employs a method known as error backpropagation in which the weight associated with each connection is adjusted. The total error at the output layer given in equation (5) is then reduced by redistributing this error value backwards through the hidden layers until the input layer is reached.

$$
\begin{aligned}
& \text { Forward equation (activation) } y_{i}=f\left(\text { net }_{i}\right) \\
& =f\left(\sum_{j} w_{i j} x_{j}+b_{i}\right)
\end{aligned}
$$

where $f$ (net) is the activation function; $x_{i}$ is the input from $i, w_{i j}$ is the weight of connection from unit $i$ to $j ; b_{i}$ is the bias term for each PE.

$$
\begin{aligned}
& \text { Backpropagation equation (error) } e_{i} \\
& =-\varepsilon_{i}+\sum_{j>i} w_{j i} \delta_{j}
\end{aligned}
$$

where $\delta$, the summation index enforces $j>i, e$ and $\varepsilon$ are the produced and injected error. The error is 


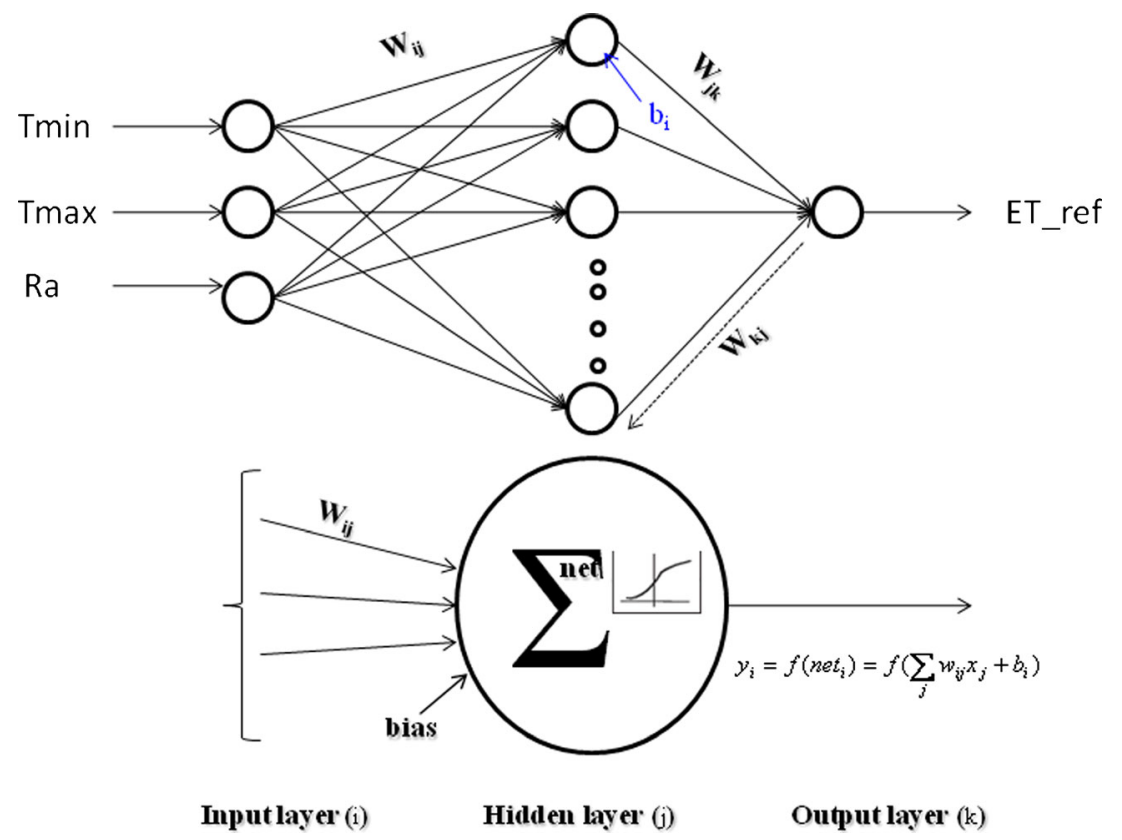

Figure 2. Structure of a BP model typology.

propagated from the output layer to the input layer for updating the weights of connections according to the gradient equation given as:

$$
\Delta w_{i j}=-\eta \frac{\partial E}{\partial w_{i j}}=-\eta y_{j} \delta_{i}
$$

and

$$
w_{i j}(n+1)=w_{i j}(n)+\Delta w_{i j}(n),
$$

where the step size $\eta$ is called the learning rate, $\delta_{i}$ is a sum of local errors at each network output $\mathrm{PE}$, scaled by the weights connecting the output PEs to the $i$ th PE. $\delta_{i}$ computes the total error reaching the $i$ th $\mathrm{PE}$ from the output layer as $\delta_{i}(n)=f^{\prime}\left(\operatorname{net}_{i}(n)\right) \sum_{k} \delta_{k} w_{k i}(n)$. This process is repeated until the total error for all datasets is sufficiently small. Since it is very easy for training process to be trapped in a local minimum, the momentum term to the weight change is added. The momentum coefficient $(\alpha)$ keeps the network moving and stabilizes its convergence. In momentum learning, the change of weight is computed as follows:

$$
\Delta w_{i j}(n+1)=-\eta y_{j} \delta_{i}+\alpha \Delta w_{i j}(n) .
$$

\subsection{Data boundaries set}

It is essential to scale the data for avoiding the problem associated with extreme values in the network. Hence, the data employed have been bounded between zero and 1 by using the following equation, which was suggested by Kumar et al. (2002):

$$
y_{\text {norm }}=\frac{y_{i}-y_{\min }}{y_{\max }-y_{\min }}
$$

where $y_{\text {norm }}$ is the normalized dimensionless variable; $y_{i}$ is the observed value of variable; then $y_{\min }$ and $y_{\max }$ are the minimum and the maximum values of the observed variable.

\subsection{Models' performances evaluation}

The statistical indicators employed to compare the models' performances are the root mean square error (RMSE), mean absolute error (MAE) and coefficient of determination $\left(r^{2}\right)$, and they are expressed as the following:

$$
\begin{gathered}
\mathrm{RMSE}=\sqrt{\frac{\sum_{i=1}^{N}\left(y_{i}-y_{i}^{\prime}\right)^{2}}{N}} \\
\operatorname{MAE}=\frac{1}{N} \sum_{i=1}^{N}\left|y_{i}-y_{i}^{\prime}\right| \\
r^{2}=\left(\frac{\sum_{i-1}^{N}\left(y_{i}-\bar{y}\right)\left(y_{i}^{\prime}-\bar{y}^{\prime}\right)}{\sqrt{\sum_{i=1}^{N}\left(y_{i}-\bar{y}^{\prime}\right)^{2} \sum_{i=1}^{N}\left(y_{i}-\bar{y}^{\prime}\right)^{2}}}\right)^{2},
\end{gathered}
$$

where $y_{i}$ represents the PM observed ET_ref, $y_{i}^{\prime}$ is the alternative method's estimated ET_ref for the $i$ th values; $\bar{y}$ and $\bar{y}^{\prime}$ represent the average values of 
the corresponding variable; and $N$ represents the number of data considered. Additionally, a linear regression $y=\alpha_{1} x+\alpha_{0}$ is applied for evaluating the models' performance statistically, where $y$ is the dependent variable (alternative methods); $x$ the independent variable $(\mathrm{PM}) ; \alpha_{1}$ the slope and $\alpha_{0}$ the intercept.

\section{Results and discussion}

\subsection{Network configuration}

Feed forward backpropagation neural network (BP) was used to forecast ET_ref from temperature database. Hence, the network was fed with minimum and maximum air temperatures, and extraterrestrial solar radiation. The determination of the optimum processing element (PE) in the hidden layer providing the best testing results was the initial process of the learning procedure. According to Parasuraman et al. (2007), one of the important issues in the development of neural networks model is the determination of the optimal number of processing elements that can satisfactorily capture the nonlinear relationship existing between the input and the output variables. There are no fixed rules for developing a neural network model with predefined optimum number of PE. Since no clearcut guidelines are available according to Vemuri (1992), the trial-and-error method was decided. The number of $\mathrm{PE}$ in the hidden layer was varied between 1 and 20. The optimum number in the hidden layer was found at 9 PEs based on the RMSE and $r$ evaluation. Figure $3(\mathrm{a}$ and $\mathrm{b}$ ) shows the network performances under the variation of the processing elements. The configuration of the BP model with 9 PEs was adopted during the network learning process. This study also adopted a single hidden layer since it is well known that one hidden layer is enough to represent the ET_ref nonlinear relationship (Zanetti et al. 2007; Traore et al. 2010a).

\subsection{ET_ref forecasting}

Table 1 presents the statistical performances of RMBF, BCR and BP1 based on temperatures data. Figure 4(a and b) shows the scatter plots between observed and estimated output during the training and cross-validation periods of $\mathrm{BP} 1$ using minimum and maximum air temperatures, and extraterrestrial solar radiation data. It is noted that the estimated outputs by the BP1 model fit well with the observed values. During the testing period, the statistical evaluation results obtained with BP1 based only on temperature data are $0.912,0.476 \mathrm{~mm}$ day $^{-1}$ and $0.411 \mathrm{~mm}$ day $^{-1}$
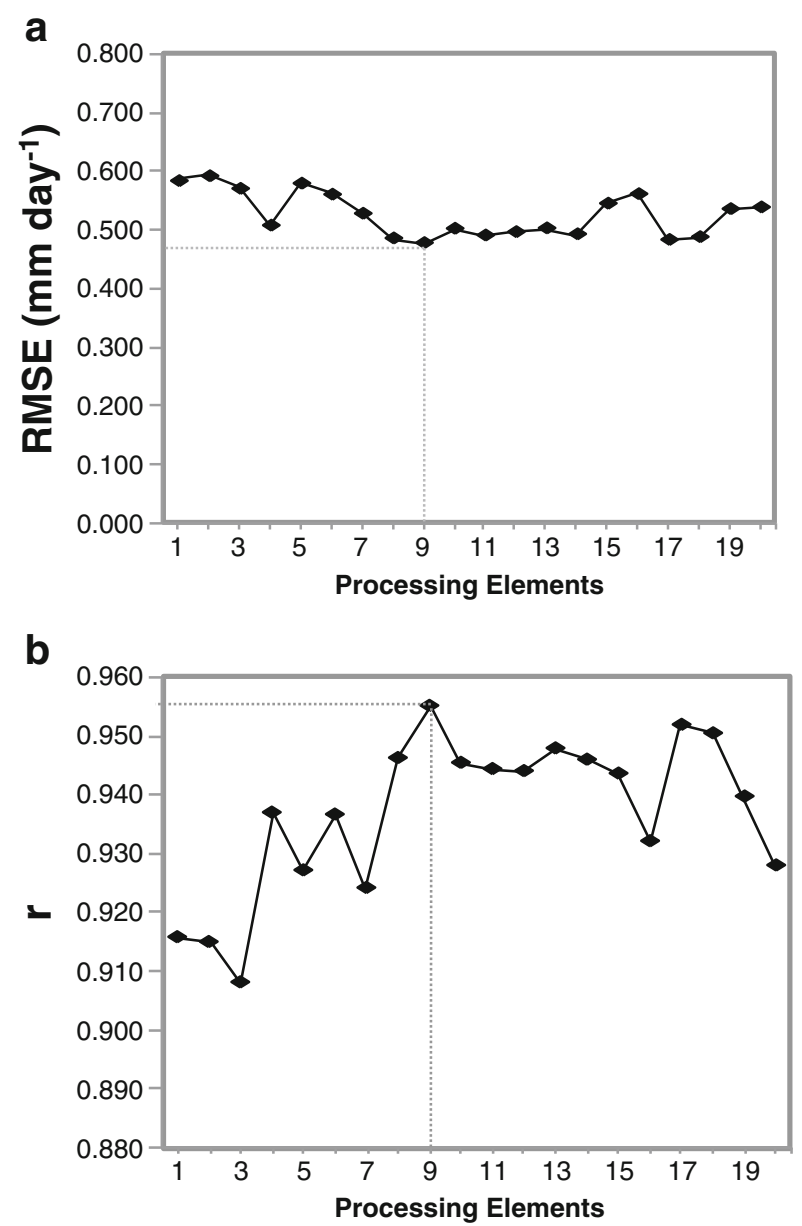

Figure 3. Neural network accuracy for different number of processing elements in ET_ref forecasting during the testing period in Dédougou region: RMSE (a) and $r(\mathbf{b})$.

for $r^{2}$, RMSE and MAE, respectively. While the results with $\mathrm{BCR}$ are $0.668,0.725 \mathrm{mmday}^{-1}$, and $0.509 \mathrm{mmday}^{-1}$ for $r^{2}$, RMSE and MAE, respectively. RMBF produces the poorest performance results with $0.665,0.800 \mathrm{mmday}^{-1}$ and $0.591 \mathrm{~mm} \mathrm{day}^{-1}$ for the $r^{2}$, RMSE and MAE, respectively. The BP1 neural network produces the best result based on the $r^{2}$, RMSE and MAE. Based upon these performances, it was observed that there is a difference in ranking the models with BP1 temperature-based at the top, followed by BCR and RMBF. The deviation between BP1 and PM estimates ET_ref values are less than $1 \mathrm{~mm}$ day $^{-1}$. Figure 5 shows the models' estimated ET_ref gridding map generated over the minimum and maximum air temperatures during the testing period. From figure 5, BP1 produced the closest ET_ref contour trends to PM. Meanwhile, RMBF and BCR showed completely different trends to PM due to their poor performances in estimating ET_ref in the region. These two models towards the period considered overestimated and underestimated ET_ref to some extent in the region, 
Table 1. Statistical summary of the models performances during the testing period estimation in the study area.

\begin{tabular}{|c|c|c|c|c|c|c|}
\hline Model & Input variable & $\alpha_{1}$ & $\alpha_{0}$ & $r^{2}$ & $\begin{array}{c}\text { RMSE } \\
\left(\mathrm{mm} \mathrm{day}^{-1}\right)\end{array}$ & $\begin{array}{c}\text { MAE } \\
\left(\mathrm{mm} \mathrm{day}^{-1}\right)\end{array}$ \\
\hline $\mathrm{RMBF}$ & $T_{\max }, T_{\min }, T_{\text {mean }}, R_{a}, p$ & 0.530 & 2.652 & 0.665 & 0.800 & 0.591 \\
\hline BCR & $T_{\text {mean }}, p$ & 0.616 & 2.380 & 0.668 & 0.725 & 0.509 \\
\hline $\mathrm{BP} 1$ & $T_{\max }, T_{\min }, R_{a}$ & 0.911 & 0.862 & 0.912 & 0.476 & 0.411 \\
\hline
\end{tabular}
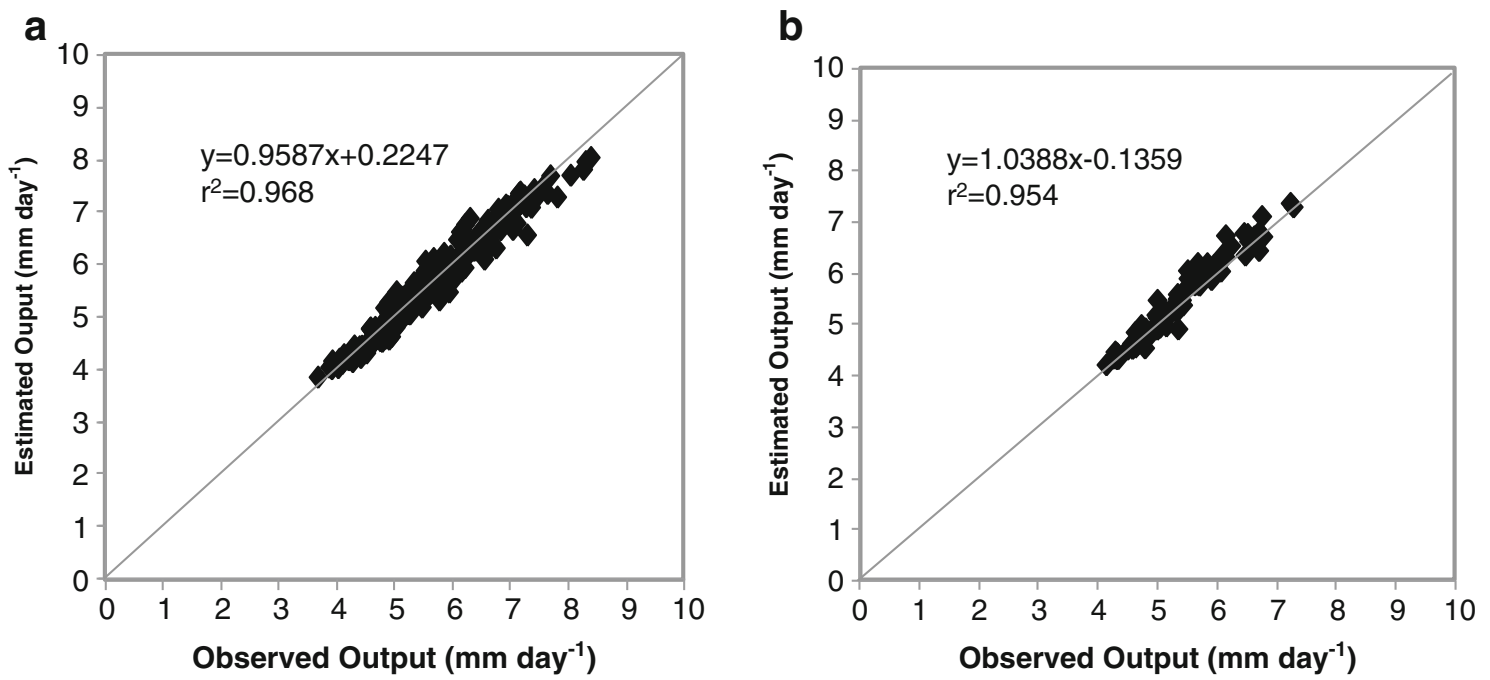

Figure 4. Scatter plots comparison between observed and estimated output during the BP1 training (a) and cross-validation (b) periods in Dédougou region.

which probably explain their inconsistency contour trends observed from the maps. The performance statistics from table 1 also showed obviously that BP1 has a slope close to 1 with the lowest intercept value when compared to RMBF and BCR. The conventional models show clearly poor performance results in comparison with $\mathrm{BP} 1$. In the past, Khoob (2008a, b) achieved remarkable studies in ET_ref estimation by using similar input datasets with the BP neural network.

From plotting analysis, the ET_ref comparison results between conventional models and PM taken as reference values showed an underestimation and overestimation between December and July, and between September and November, respectively. Noted that the underestimation occurred in dry season (high wind speed period) while the overestimation occurred in rainy season (moderate wind speed). In general, the conventional methods due to their models' simplicity are unable to capture the effect of some important climatic parameters, which affect ET_ref. The behaviour of these conventional models could be explained by the influence of other parameters such as wind, which is not considered into the model. The weather conditions of the study area characterized by a low rainfall, high temperature variation and high wind speed might affect the accuracy of ET_ref estimation from temperature database. For BCR, similar over or underpredicted results of ET_ref in the semiarid environment have been revealed in George et al. (2002), Hossein et al. (2004) and Traore et al. (2008) studies. According to Mohan (1991), the low performance of BCR in semiarid climates is evidently due to the lowest degrees of correlation between temperature variables and ET_ref. The performance of the conventional methods strongly dependent of climatic condition. George et al. (2002) indicated that, the accuracy of these methods varies with climatic conditions. This is also true for RMBF since its input structure is based on temperature data only. There is therefore a consensus that, the performances of most alternative methods have been found to vary from one climate to another (Nandagiri and Kovoor 2006). Since the BP1 showed high performance compared to the conventional temperature-based methods of BCR and RMBF, this algorithm can be considered as a potential alternative approach for forecasting the ET_ref in the semiarid zone of Africa. The accuracy of the BP1 might be improved by considering wind speed, which has been identified by Wang et al. (2007) as a serious variable affecting significantly the ET_ref in northern Burkina Faso. In order to understand the influence of wind on ET_ref in this semiarid environment, the sensitivity 

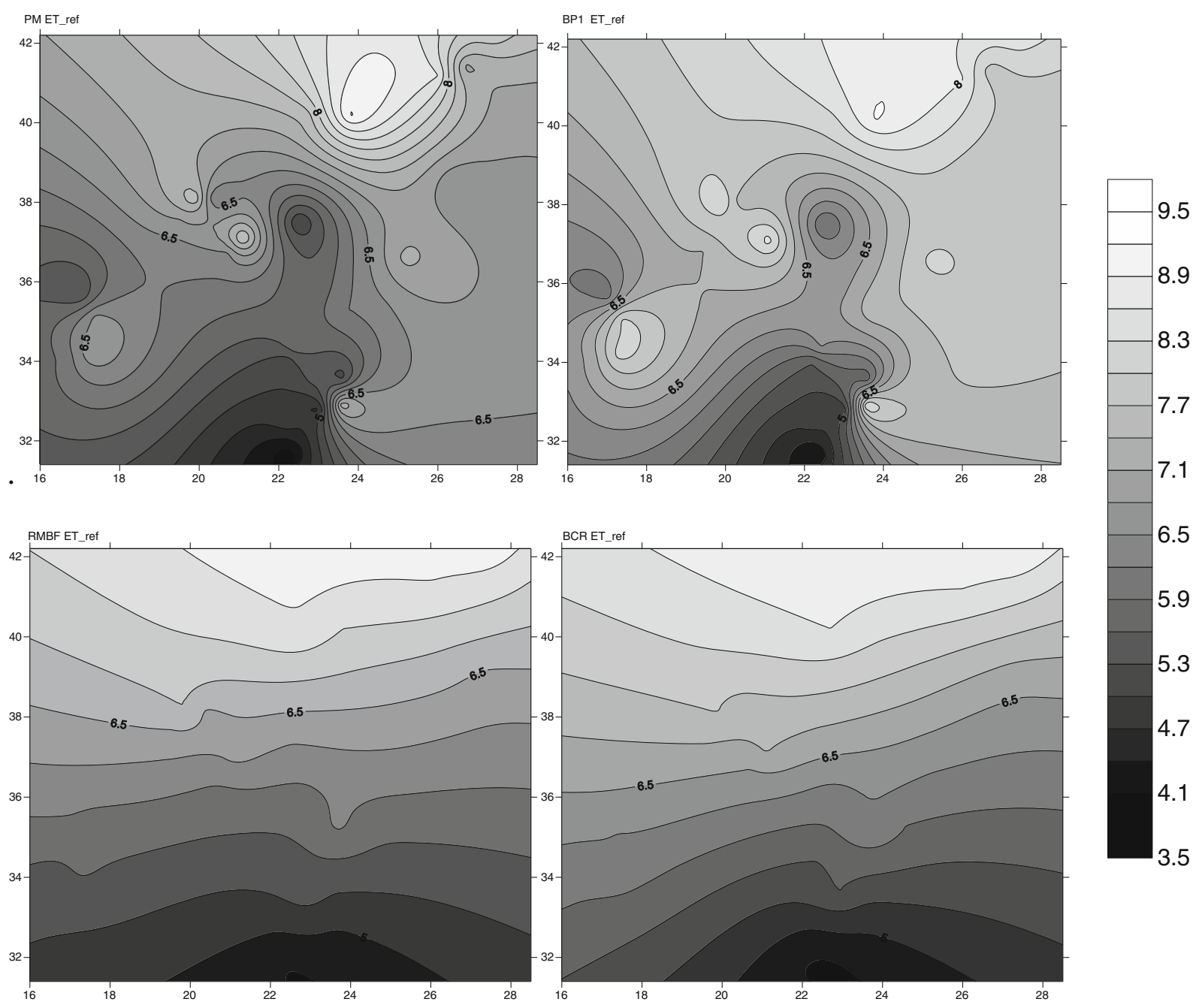

Figure 5. Models estimated ET_ref contours grid map over the air temperature data in Dédougou region.

analysis was carried out by considering wind speed as an additional input variable of the neural network.

\subsection{Network accuracy increment}

Figure 6 shows the typical climatic characterization of the study area. In general, the spatial distribution map from the meteorological data showed significant change between the northern and western south regions of the country (figure 6). The region receives less than $1000 \mathrm{~mm}$ of annual rainfall, and figure $6(\mathrm{a}$ and $\mathrm{b})$ shows that both precipitation and relative humidity values are not significantly high. Meanwhile, air temperature values in the region are among the highest in the country except in the northern regions (figure $6 \mathrm{c}$ and $\mathrm{d}$ ). Under the consideration of the sensitivity study, additional meteorological variables have been considered in the neural network input datasets for estimating the ET_ref. Table 2 summarizes the models' statistical performances with the additional variables during the testing period estimation. By inserting both relative humidity and sunshine into the network models input set (BP3 and BP4), the models' performances are reduced. Despite the high value of sunshine duration in the region of Dédougou (figure 6e), it does not improve the network performance. However, wind speed alone (BP2) provided high accuracy value as shown in figure 7 with BP2. The darker shades in figure 7 are for lower ET_ref values. The performances with relative humidity and sunshine are not as good as with wind velocity. It is also clearly observed from figure 6(f) that wind speed spatial distribution map around the country has a strong effect illustrated by the blue colour where the meteorological station is located. Indeed, figure 6(f) highlights in Burkina Faso interesting wind tunnel phenomenon materializing in blue, yellow and green colours. Obviously, this typical climatic condition strongly recommends disposing more than one meteorological station in the southern part of Dédougou region. Therefore, care must be taken with the wind velocity since it has strong effect on ET_ref. 

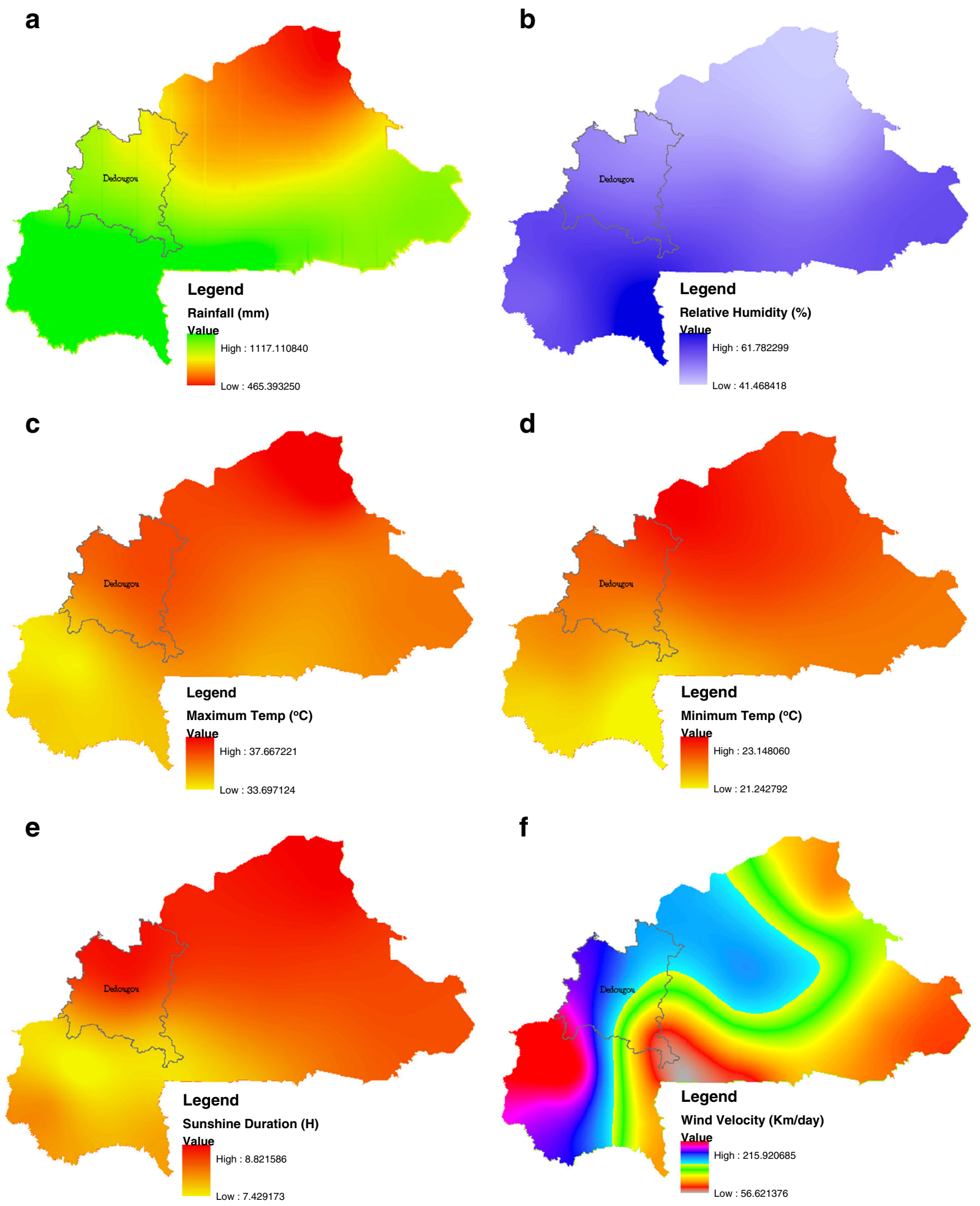

Figure 6. Climatic parameters distribution map across the country between 1996 and 2007: (a) rainfall; (b) relative humidity; (c) minimum temperature; (d) maximum temperature; (e) sunshine duration; and (f) wind velocity.

For this windy region as given in table 2, BP2 accuracy improves significantly with the addition of wind speed into the network and the $r^{2}$, RMSE and MAE obtained are $0.965,0.255 \mathrm{mmday}^{-1}$ and $0.176 \mathrm{mmday}^{-1}$, respectively. The wind speed increases significantly the coefficient of determination $\left(r^{2}\right)$ of the network from 0.912 to 0.965. Furthermore, the wind changes drastically the $r^{2}$ with $5.81 \%$ increase, and reduces significantly the RMSE and MAE. These good results are evidenced by BP5 model in figure 7 showing similar trends with PM. These results tell us the high 
Table 2. Models statistical performances during the testing period with the addition of the wind, sunshine and relative humidity variables for the sensitivity study.

\begin{tabular}{|c|c|c|c|c|c|c|}
\hline Model & Input variable & $\alpha_{1}$ & $\alpha_{0}$ & $r^{2}$ & $\begin{array}{c}\text { RMSE } \\
\left(\mathrm{mm} \mathrm{day}^{-1}\right)\end{array}$ & $\begin{array}{c}\text { MAE } \\
\left(\mathrm{mm} \mathrm{day}^{-1}\right)\end{array}$ \\
\hline BP2 & $T_{\max }, T_{\min }, R_{a}$, wind & 0.973 & 0.181 & 0.965 & 0.255 & 0.176 \\
\hline BP3 & $T_{\max }, T_{\min }, R_{a}, \mathrm{Rh}$ & 0.913 & 0.378 & 0.886 & 0.526 & 0.423 \\
\hline $\mathrm{BP} 4$ & $T_{\max }, T_{\min }, R_{a}, \mathrm{Rh}, \mathrm{Sun}$ & 0.904 & 0.408 & 0.867 & 0.552 & 0.451 \\
\hline BP5 & $T_{\max }, T_{\min }, R_{a}, \mathrm{Rh}$, Sun, wind & 1.009 & -0.072 & 0.980 & 0.215 & 0.126 \\
\hline
\end{tabular}
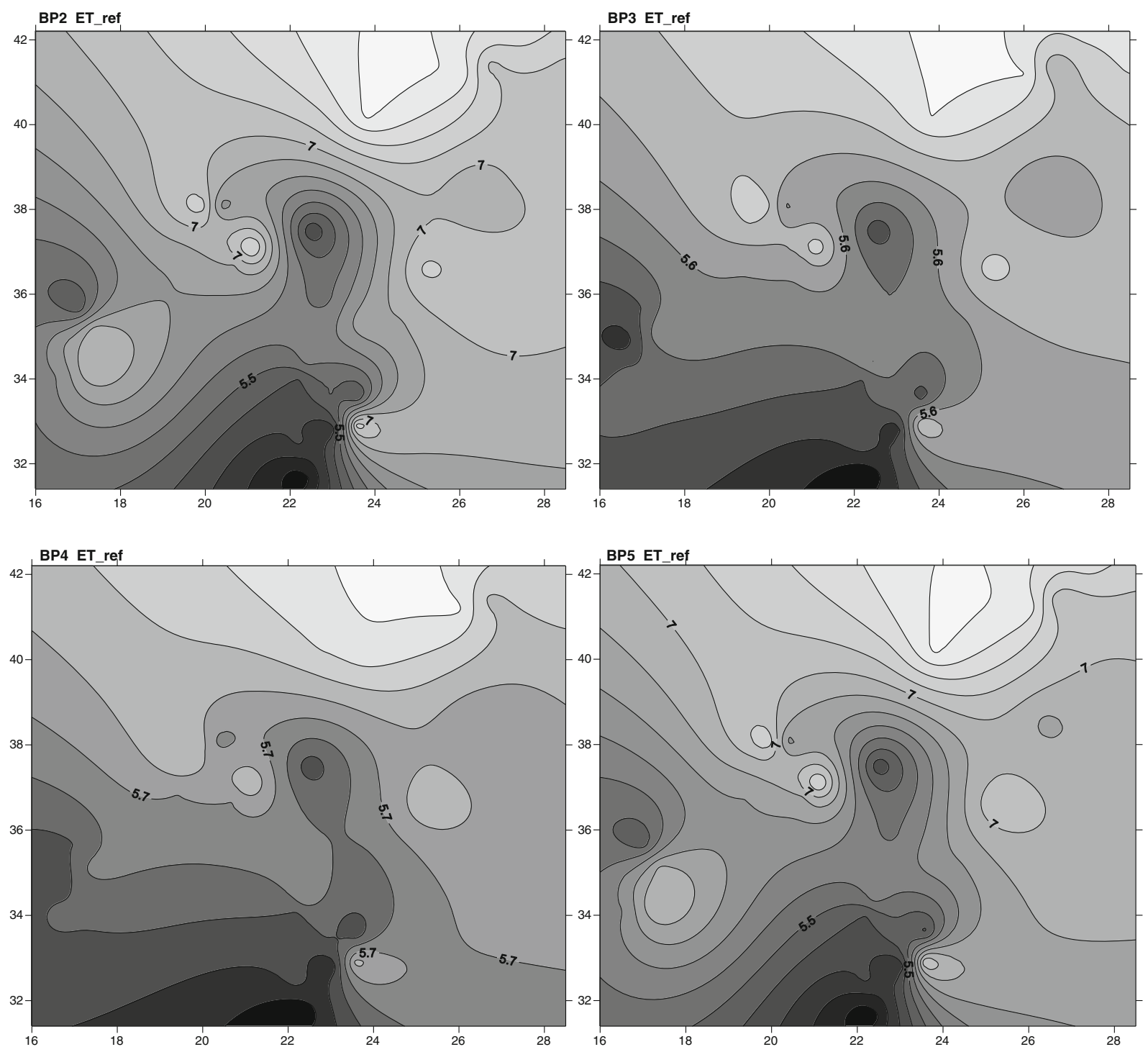

Figure 7. BP estimated ET_ref comparative gridding map during the testing period when wind velocity, relative humidity and sunshine variables are incorporated into the neural network input set.

sensitivity of ET_ref for the wind speed under the Dédougou weather condition. ET_ref is sensitive to wind (Fisher et al. 2005) and its performance may be influenced (Xiaoying and Erda 2005). Hess (1999) found a positive correlation between ET_ref and wind speed in the East Arid Zone of Nigeria in Africa. It is well documented at least by Allen et al. (1998) and Temesgen et al. (1999) that, the climatic parameter such as wind velocity simultaneously results by deteriorating ET_ref from temperature-based methods. Kizgi and Ozturk (2007) by using the ANN found that the wind 
speed is the most effective variable in estimating ET_ref with the temperature-based method. According to Popova et al. (2006), the impact of wind speed on the ET_ref results is relatively smaller except for arid windy areas.

The deviation between both $\mathrm{BP}$ wind models and PM estimates ET_ref values have lowest value at $-0.189 \mathrm{~mm} \mathrm{day}^{-1}$. This indicates that the BP wind models produce very close values to PM with small errors margin. In addition, the slopes of the linear regression equations are close to 1 and the intercepts decrease significantly. Wind speed is extremely required to be in the model for the neural network accuracy improvement in this African semiarid zone. When wind data is not available, ET_ref can still be better estimated with the BP1 than BCR and RMBF by using air temperature and extraterrestrial radiation data.

\section{Conclusions}

The PM is a universal physical-based model requiring enormous climatic data, which are missing in developing countries particularly in African semiarid zones. Therefore, this study adopted an approach using few input variables since the complete meteorological data are not always available in the production areas in Burkina Faso. The accurate estimation of evapotranspiration is crucial for an efficient agriculture water management in the area where there is water resources rarity problem. The results from the statistical evaluation indicated that BP performs better than BCR and RMBF conventional methods. In poor data situation, BP based only on temperature data is much more preferred in ET_ref forecasting than the conventional methods employed in this semiarid zone studied here. In addition, it has been observed that the accuracy of the BP improves significantly when wind speed is inserted into the neural network model. For high efficient management of agricultural water, which involves accurate ET_ref, wind speed is an essential variable and highly recommended to be taken into account in the model for this semiarid zone of Africa. The current developed model can, therefore, be suggested to estimate ET_ref for Dédougou region in Burkina Faso. It is possible to forecast ET_ref in Burkina Faso through backpropagation neural network methodology using only air temperature data.

\section{Acknowledgements}

The authors acknowledge the Ministry of Agriculture, Hydraulic and Fisheries Resources of Burkina Faso for advising, collecting, and providing the data used in the study. The financial support provided by the International Cooperation and Development Fund (Taiwan ICDF) and NSC1012625-M-020-003 is highly appreciated.

\section{References}

Alexandris S, Kerkides P and Liakatas A 2006 Daily reference evapotranspiration estimates by the Copais approach; Agr. Water Manag. 82 371-386.

Allen R G, Pereira L S, Raes D and Smith M 1998 Crop evapotranspiration, guideline for computing water requirements; Irrigation Drainage Paper No 56, FAO, Rome, Italy.

Doorenbos J and Pruitt W O 1977 Guidelines for predicting crop water requirements; In: FAO Irrigation and Drainage Paper, No 24, 2nd edn, FAO, Rome, 179p.

Firat M 2008 Comparison of artificial intelligence techniques for river flow forecasting; Hydrol. Earth Syst. Sci. 12 $123-139$.

Fisher J B, Terry A, DeBiase A, Qi1 Y, Xu M and Allen H 2005 Evapotranspiration models compared on a Sierra Nevada forest ecosystem; Environ. Model. Softw. 20 $783-796$.

George B A, Reddy B R S, Raghuwanshi N S and Wallender W W 2002 Decision support system for estimating reference evapotranspiration; J. Irrig. Drain. Eng. 128 $1-10$.

Hess T M 1999 Trends in reference evapotranspiration in the northeast arid zone of Nigeria; J. Arid Environ. 38 99-115.

Hossein D, Yamamoto T and Rasiah V 2004 Assessment of evapotranspiration estimation models for use in semi-arid environments; Agr. Water Manag. 64 91-106.

Kant Y and Badarinath K V S 1998 Regional scale evapotranspiration estimation using satellite derived albedo and surface temperature; J. Indian Soc. Remote Sens. 26(3) 129-134.

Kerh T, Wang Y M, Hsu G S and Gunaratnam D 2009 Forecasting of nonlinear shoreline variation based on aerial survey map by Neural Network Approach; Int. J. Nonlin. Sci. Num. 10(9) 1211-1221.

Kiz̧i O 2006 Generalized regression neural networks for evapotranspiration modelling; Hydrol. Sci. J. 51(6) 1092-1104.

Kiz̧i O and Ozturk O 2007 Adaptive neurofuzzy computing technique for evapotranspiration estimation; J. Irrig. Drain. Eng. 133(4) 368-379.

Khoob A R 2008a Comparative study of Hargreaves's and artificial neural network's methodologies in estimating reference evapotranspiration in a semiarid environment; Irrig. Sci. 26(3) 253-259.

Khoob A R 2008b Artificial neural network estimation of reference evapotranspiration from pan evaporation in a semi-arid environment; Irrig. Sci. 27(1) 35-39.

Kumar M, Raghuwanshi N S, Singh R, Wallender W W and Pruitt W O 2002 Estimating evapotranspiration using artificial neural network; J. Irrig. Drain. Eng. 128(4) $224-233$.

Landeras G, Ortiz-Barredo A and Lopez J J 2008 Comparison of artificial neural network models and empirical and semi-empirical equations for daily reference evapotranspiration estimation in the Basque Country (Northern Spain); Agr. Water. Manag. 95 553-565.

Marti P and Gasque M 2010 Ancillary data supply strategies for improvement of temperature-based ETo ANN models; Agr. Water Manag. 97(7) 939-955. 
Marti P, Royuela A, Manzano J and Palau G 2010 Generalization of ETo ANN models through data supplanting; J. Irrig. Drain. Eng. 136(3) 161-174.

Meza F J 2005 Variability of reference evapotranspiration and water demands. Association to ENSO in the Maipo river basin, Chile; Global Planet. Change 47 212-220.

Mohan S 1991 Intercomparison of evapotranspiration estimates; Hydrol. Sci. J. 36(5) 447-460.

Nandagiri L and Kovoor G 2006 Performance evaluation of reference evapotranspiration equations across a range of Indian climates; J. Irrig. Drain. Eng. 132(3) 238-249.

Parasuraman K, Elshorbagy A and Carey S K 2007 Modelling the dynamics of the evapotranspiration process using genetic programming; Hydrol. Sci. J. 52(3) $563-578$.

Popova Z, Kercheva M and Pereira L S 2006 Validation of the FAO methodology for computing ETo with limited data: Application to south Bulgaria; Irrig. Drain. 55 201-215.

Smith M, Allen R and Pereira L 1996 Revised FAO methodology for crop water requirements; In: Proceeding of the ASAE International Conference on Evapotranspiration and Irrigation Scheduling, 3-6 November, San Antonio, Texas, pp. 116-123.

Sudheer K P, Gosain A K and Ramasastri K S 2003 Estimating actual evapotranspiration from limited climatic data using neural computing technique; J. Irrig. Drain. Eng. 129(3) 214-218.

Temesgen B, Allen R G and Jensen D T 1999 Adjusting temperature parameters to reflect well-water conditions; J. Irrig. Drain. Eng. 125 26-33.

Traore S, Wang Y M, Kerh T and Ouedraogo A 2007 Application of CROPWAT simulation model for rainfed and irrigated agriculture water planning in Burkina Faso; J. Int. Coop. 2(1) 43-64.

Traore S, Wang Y M and Kerh T 2008 Modeling reference evapotranspiration by generalized regression neural network in semiarid zone of Africa; WSEAS Trans. Infor. Sci. Appl. 6(5) 991-1000.

Traore S, Wang Y M and Kerh T 2010a Artificial Neural Network for Modeling Reference Evapotranspiration Complex Process in Sudano-Sahelian Zone; Agr. Water Manag. J 97 707-714.
Traore S, Wang Y M, Kan C E and Kerh T 2010b A mixture neural methodology for computing rice consumptive water requirements in FadaN'Gourma Region, Eastern Burkina Faso; Paddy Water Environ. J., doi: 10.1007/s10333-009-0195-5.

Vemuri V R 1992 Artifical neural networks: Concepts and control application; IEEE Computer Society Press, Los Alamitos, CA.

Wang Y M, Traore S and Kerh T 2007 Assessment of evapotranspiration based on data information models at production sites in Burkina Faso; WSEAS Trans. Comput. 6(6) $880-887$.

Wang Y M, Traore S and Kerh T 2008 Computing and modeling for crop yields in Burkina Faso based on climatic data information; WSEAS Trans. Infor. Sci. Appl. 5(7) 832-842.

Wang Y M and Traore S 2009 Time-lagged recurrent network for forecasting episodic event suspended sediment load in typhoon prone area; Int. J. Phys. Sci. 4(9) 519-528.

Wang Y M, Traore S and Kerh T 2009a Computational performance of reference evapotranspiration in semiarid zone of Africa; Sci. Res. Essays 6(4) 577-583.

Wang Y M, Traore S and Kerh T 2009b Applying evapotranspiration reference model and rainfall contribution index for agricultural water; Afr. J. Agr. Res. 4(12) 1493-1504.

Wang Y M, Namaona W, Traore S and Zhang Z C 2009c Seasonal temperature-based models for reference evapotranspiration estimation under semi-arid condition of Malawi; Afr. J. Agr. Res. 4(9) 878-886.

Wang Y M, Kerh T and Traore S 2009d Neural Networks Approaches for modelling river suspended sediment concentration due to tropical storms; Global NEST J. 11(4) 457-466.

Xiaoying L and Erda L 2005 Performance of the PriestleyTaylor equation in the semi-arid climate of north China; Agr. Water Manag. 71 1-17.

Zanetti S S, Sousa E F, Oliveira V P S, Almeida F T and Bernardo S 2007 Estimating evapotranspiration using artificial neural network and minimum climatological data; J. Irrig. Drain. Eng. 133(2) 83-89. 